\title{
WILLIAM BLAKE EM ESPANHOL
}

\author{
WILLIAM BLAKE IN SPANISH
}

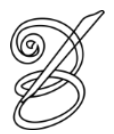 \\ Juliana STEIL ${ }^{1}$ \\ Professora Adjunta (área de Tradução) \\ Universidade Federal de Pelotas (UFPel) \\ Pelotas, Rio Grande do Sul, Brasil \\ julianasteil@gmail.com \\ Vitória Tassara Costa SILVA ${ }^{2}$ \\ Graduanda em Letras Bacharealdo - Tradução Português/Inglês \\ Universidade Federal de Pelotas \\ Pelotas, Rio Grande do Sul, Brasil \\ vitoriatassara@hotmail.com
}

Resumo: Esse documento é uma compilação de informações recolhidas sobre as traduções das obras de William Blake publicadas em espanhol, bem como uma análise inicial acerca de seu prestígio literário neste idioma.

Abstract: This document is a compilation of information gathered about translations of William Blake's works published in Spanish, as well as an initial analysis of the author's literary reputation in that language.

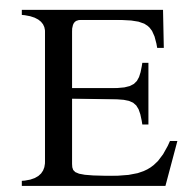

ste arquivo apresenta um levantamento das traduções de obras de William Blake (1757-1827) publicadas em língua espanhola e uma análise inicial da imagem literária do autor neste idioma. Formam o suporte teórico deste trabalho especialmente os estudos de Itamar Even-Zohar (1990) e de André Lefevere (2007).

Um objetivo importante dos estudos descritivos com base na proposta teórica de EvenZohar (1990) é verificar as condições particulares nas quais uma literatura recebe interferência de outra e observar quais elementos são transferidos de uma literatura para a outra. Nesse caso, a literatura traduzida faz parte da literatura da cultura-alvo - não sendo um elemento separado do polissistema de chegada, e alcançando nele, muitas vezes, uma posição central (EVENZOHAR, 2012).

Ao considerar a tradução literária um fenômeno do polissistema de chegada, EvenZohar já destaca a participação decisiva dos tradutores e editores, entre outros, na elaboração dos textos traduzidos, de modo que não existe uma passagem neutra de obras literárias de um sistema a outro. Levando em conta este argumento, Lefevere desenvolveu a ideia de tradução 
como forma de reescrita. A reescrita seria a re-apresentação de uma obra, como acontece no caso da edição, da crítica, da tradução, entre outras modalidades. Lefevere (2007) argumenta que os reescritores são tão responsáveis pela propagação e recepção de obras literárias quanto os autores, e que, ao lermos direta ou indiretamente uma obra literária, temos acesso a uma imagem ou construto dessa obra.

O presente trabalho procura observar a presença de William Blake nos sistemas literários de língua espanhola via literatura traduzida, de modo que os dados sobre as traduções podem mostrar quais textos da obra do poeta inglês foram, ou têm sido, importantes para as literaturas de língua espanhola.

Nesse sentido, foi realizada uma busca de títulos traduzidos do autor (em formato livro) no sistema virtual de pesquisa do acervo das bibliotecas nacionais dos países hispanófonos. Foram consultados também sites de livrarias e de vendas de livros, além das bibliografias de Bentley Jr (2015) e a web em geral. Com o cruzamento destas fontes, foram reunidos e sistematizados os seguintes dados sobre as traduções: país de origem, título da obra original, título da obra traduzida, edição, editora, nome do tradutor, idiomas da edição (edição bilíngue

192 ou não), obra ilustrada (com reproduções das gravuras originais ou não) e ano da publicação.

O quadro a seguir mostra as informações encontradas sobre as traduções de textos de Blake para o espanhol publicadas em países da América Latina ${ }^{3}$. 


\begin{tabular}{|c|c|c|c|c|c|c|c|c|}
\hline País & $\begin{array}{c}\text { Título } \\
\text { Original }\end{array}$ & $\begin{array}{l}\text { Título da } \\
\text { Tradução }\end{array}$ & Edição & Editora & Tradutor & $\begin{array}{l}\text { Idiomas da } \\
\text { Edição }\end{array}$ & Ilustrações & Ano \\
\hline Argentina & {$[*]$} & Poemas y profecias & $*$ & Córdoba: Assandri & $*$ & Espanhol & $*$ & 1957 \\
\hline Argentina & $\begin{array}{l}\text { The Marriage } \\
\text { of Heaven and } \\
\text { Hell }\end{array}$ & $\begin{array}{l}\text { Matrimonio del } \\
\text { cielo y el infierno }\end{array}$ & $*$ & Galerna & Diego Arenas & Espanhol & $*$ & 1979 \\
\hline Argentina & $\begin{array}{l}\text { Songs of } \\
\text { Innocence }\end{array}$ & $\begin{array}{l}\text { Cantos de } \\
\text { Inocencia }\end{array}$ & $*$ & $\begin{array}{l}\text { Adiax,Buenos } \\
\text { Aires }\end{array}$ & Mirta Rosenberg & Espanhol & $*$ & 1980 \\
\hline Argentina & {$[*]$} & Poesía Completa & $*$ & Hyspamérica & $*$ & Espanhol & $*$ & 1986 \\
\hline Argentina & $\begin{array}{l}\text { Songs of } \\
\text { Innocence and } \\
\text { of Experience }\end{array}$ & $\begin{array}{l}\text { Cantares de } \\
\text { Inocencia y } \\
\text { Experiencia: que } \\
\text { Muestran los Dos } \\
\text { Estados Contrarios } \\
\text { del Alma Humana } \\
\end{array}$ & $12^{\circ}$ & $\begin{array}{l}\text { Buenos Aires: } \\
\text { Errepar, S.A. }\end{array}$ & Miguel Grinberg & Espanhol & $*$ & 2000 \\
\hline Argentina & $\begin{array}{l}\text { Tiriel, The } \\
\text { Book of Thel }\end{array}$ & $\begin{array}{l}\text { Tiriel, El libro de } \\
\text { Thel }\end{array}$ & $*$ & Artemisa & Jordi Doce & $\begin{array}{l}\text { Inglês - } \\
\text { Espanhol }\end{array}$ & $*$ & 2006 \\
\hline Argentina & {$[*]$} & Poesía Completa & $1^{\mathrm{a}}$ & Cygnus Regalis & Andrés Maldonado & $\begin{array}{l}\text { Inglês - } \\
\text { Espanhol }\end{array}$ & $*$ & 2012 \\
\hline Argentina & $\begin{array}{l}\text { The Marriage } \\
\text { of Heaven and } \\
\text { Hell }\end{array}$ & $\begin{array}{l}\text { El matrimonio del } \\
\text { cielo y del infierno }\end{array}$ & $*$ & $\begin{array}{l}\text { Buenos Aires: Ed. } \\
\text { del Mediodía }\end{array}$ & $*$ & Espanhol & $*$ & $*$ \\
\hline
\end{tabular}




\begin{tabular}{|c|c|c|c|c|c|c|c|c|}
\hline País & $\begin{array}{c}\text { Título } \\
\text { Original }\end{array}$ & $\begin{array}{l}\text { Título da } \\
\text { Tradução }\end{array}$ & Edição & Editora & Tradutor & $\begin{array}{l}\text { Idiomas da } \\
\text { Edição }\end{array}$ & Ilustrações & Ano \\
\hline México & $\begin{array}{l}\text { The Marriage } \\
\text { of Heaven and } \\
\text { Hell }\end{array}$ & $\begin{array}{l}\text { El matrimonio del } \\
\text { cielo y del infierno }\end{array}$ & $*$ & Séneca & Xavier Vilaurrutia & Espanhol & $*$ & 1942 \\
\hline México & $\begin{array}{l}\text { Poetical } \\
\text { Sketches, } \\
\text { Songs, Thel, } \\
\text { Marriage, } \\
\text { America, } \\
\text { Urizen, The } \\
\text { Everlasting } \\
\text { Gospel, Vala, } \\
\text { Milton, } \\
\text { Jerusalem } \\
\end{array}$ & Visiones & $*$ & Editora Era & Enrique C. Trejo & $\begin{array}{l}\text { Inglês - } \\
\text { Espanhol }\end{array}$ & $*$ & 1974 \\
\hline México & $\begin{array}{l}\text { [Coleção de } \\
\text { poemas e } \\
\left.\text { ensaios }\left(^{*}\right)\right]\end{array}$ & $\begin{array}{l}\text { Primeros libros } \\
\text { proféticos: poemas }\end{array}$ & $2^{a}$ & UNAM & Agustí Bartra & Espanhol & $*$ & 1990 \\
\hline México & $\begin{array}{l}\text { The Marriage } \\
\text { of Heaven and } \\
\text { Hell }\end{array}$ & $\begin{array}{l}\text { Matrimonio del } \\
\text { cielo y del infierno }\end{array}$ & $*$ & Editora Veracruz & Xavier Vilaurrutia & $\begin{array}{l}\text { Inglês - } \\
\text { Espanhol }\end{array}$ & $*$ & 2003 \\
\hline México & $\begin{array}{l}\text { The } \\
\text { Everlasting } \\
\text { Gospel }\end{array}$ & $\begin{array}{l}\text { El Evangelio } \\
\text { Eterno }\end{array}$ & $*$ & $\begin{array}{l}\text { Cidade do Mexico: } \\
\text { Ediciones Arsenal }\end{array}$ & Evelio Rojas Robles & Espanhol & Não & 2006 \\
\hline México & $\begin{array}{l}\text { All Religions } \\
\text { Are One, } \\
\text { There is No } \\
\text { Natural } \\
\text { Religion, The }\end{array}$ & $\begin{array}{l}\text { El demonio es } \\
\text { parco: aforismos }\end{array}$ & $*$ & Verdehalago & Heriberto Yépez & Espanhol & $*$ & 2006 \\
\hline
\end{tabular}




\begin{tabular}{|c|c|c|c|c|c|c|c|c|}
\hline & $\begin{array}{l}\text { Marriage of } \\
\text { Heaven and } \\
\text { Hell; } \\
\text { "Auguries of } \\
\text { Innocence", } \\
\text { Laocoonte, } \\
\text { On Homers } \\
\text { Poetry; On } \\
\text { Virgil }\end{array}$ & & & & & & & \\
\hline México & $\begin{array}{l}\text { The Marriage } \\
\text { of Heaven and } \\
\text { Hell }\end{array}$ & $\begin{array}{l}\text { Matrimonio del } \\
\text { cielo y del infierno }\end{array}$ & $*$ & Fontamara & Xavier Vilaurrutia & $\begin{array}{c}\text { Inglês - } \\
\text { Espanhol }\end{array}$ & $*$ & 2007 \\
\hline Uruguai & $\begin{array}{l}\text { The Book of } \\
\text { Thel }\end{array}$ & El libro de Thel & $*$ & Asir & $*$ & Espanhol & $*$ & 1948 \\
\hline
\end{tabular}

O quadro a seguir mostra as traduções de obras de Blake publicadas na Espanha:

\begin{tabular}{|c|c|c|c|c|c|c|c|c|}
\hline Espanha & $\begin{array}{l}\text { The Marriage } \\
\text { of Heaven and } \\
\text { Hell, All } \\
\text { Religions Are } \\
\text { One, There Is } \\
\text { No Natural } \\
\text { Religion, } \\
\text { Tiriel, The } \\
\text { Book of Thel, } \\
\text { Visions of the } \\
\text { Daughters of } \\
\text { Albion, "A } \\
\text { Song of }\end{array}$ & $\begin{array}{l}\text { La boda del cielo y } \\
\text { del infierno }\end{array}$ & $*$ & $\begin{array}{l}\text { España Editorial } \\
\text { Mundo Latino }\end{array}$ & $\begin{array}{l}\text { Edmundo González- } \\
\text { Blanco }\end{array}$ & Espanhol & $*$ & 1928 \\
\hline
\end{tabular}




\begin{tabular}{|c|c|c|c|c|c|c|c|c|}
\hline & $\begin{array}{l}\text { Liberty", The } \\
\text { French } \\
\text { Revolution, } \\
\text { America, The } \\
\text { [First] Book of } \\
\text { Urizen, The } \\
\text { Book of } \\
\text { Ahania, The } \\
\text { Book of Los, } \\
\text { The Song of } \\
\text { Los, Europe } \\
\end{array}$ & & & & & & & \\
\hline Espanha & $\begin{array}{l}\text { The Book of } \\
\text { Urizen }\end{array}$ & El libro de Urizen & $*$ & Gráfico Editora & N.N. & $*$ & $*$ & 1947 \\
\hline Espanha & $\begin{array}{l}\text { Songs, } \\
\text { "Auguries of } \\
\text { Innocence", } \\
\text { The Marriage } \\
\text { of Heaven and } \\
\text { Hell, Visions, } \\
\text { Milton, } \\
\text { Jerusalem, The } \\
\text { Everlasting } \\
\text { Gospel } \\
\end{array}$ & $\begin{array}{l}\text { Poemas proféticos } \\
\text { y prosas }\end{array}$ & $*$ & Editora Barral & Cristóbal Serra & Espanhol & $*$ & 1971 \\
\hline Espanha & {$[*]$} & Poemas & * & $\begin{array}{l}\text { Barcelona: Plaza \& } \\
\text { Janés }\end{array}$ & Agustí Bartra & $\begin{array}{l}\text { Inglês - } \\
\text { Espanhol }\end{array}$ & $*$ & 1971 \\
\hline Espanha & $\begin{array}{l}\text { Songs of } \\
\text { Innocence and } \\
\text { of Experience } \\
\end{array}$ & $\begin{array}{l}\text { Cantos de } \\
\text { inocencia, cantos } \\
\text { de experiência }\end{array}$ & $*$ & Barcelona: Bosch & Helena Valentí & $\begin{array}{l}\text { Inglês - } \\
\text { Espanhol }\end{array}$ & $*$ & 1977 \\
\hline
\end{tabular}




\begin{tabular}{|c|c|c|c|c|c|c|c|c|}
\hline Espanha & $\begin{array}{l}\text { Songs of } \\
\text { Innocencel } \\
\text { Songs of } \\
\text { Experience }\end{array}$ & $\begin{array}{l}\text { Cantos de } \\
\text { inocencia/Cantos } \\
\text { de experiencia }\end{array}$ & $*$ & $\begin{array}{l}\text { Barcelona: } \\
\text { Editorial Bosch }\end{array}$ & $*$ & $*$ & $*$ & 1977 \\
\hline Espanha & $\begin{array}{l}\text { The Marriage } \\
\text { of Heaven and } \\
\text { Hell }\end{array}$ & $\begin{array}{l}\text { Matrimonio del } \\
\text { Cielo y del Infierno }\end{array}$ & $*$ & $\begin{array}{l}\text { Editorial Visor: } \\
\text { Madrid }\end{array}$ & Soledad Capurro & $*$ & $*$ & 1979 \\
\hline Espanha & {$[*]$} & $\begin{array}{l}\text { Blake: Poesía } \\
\text { Completa }\end{array}$ & $*$ & $\begin{array}{l}\text { Barcelona: } \\
\text { Editorial Río } \\
\text { Nuevo (Ediciones } \\
\text { 29) }\end{array}$ & Pablo Mañé Garzón & $\begin{array}{l}\text { Inglês - } \\
\text { Espanhol }\end{array}$ & $*$ & 1980 \\
\hline Espanha & $\begin{array}{l}\text { The Marriage } \\
\text { of Heaven and } \\
\text { Hell; Songs of } \\
\text { Innocence and } \\
\text { of Experience }\end{array}$ & $\begin{array}{l}\text { El matrimonio del } \\
\text { cielo y del infierno; } \\
\text { Cantos de } \\
\text { inocencia y de } \\
\text { experiencia }\end{array}$ & $*$ & Madrid: Visor & Soledad Capurro & $*$ & $*$ & 1983 \\
\hline Espanha & $\begin{array}{l}\text { Excertos de: } \\
\text { Songs, } \\
\text { "Auguries of } \\
\text { Innocence", } \\
\text { Marriage, } \\
\text { Visions, } \\
\text { Milton, } \\
\text { Jerusalem, The } \\
\text { Everlasting } \\
\text { Gospel }\end{array}$ & Antología & $*$ & $\begin{array}{l}\text { Madrid: Ediciones } \\
\text { Júcar }\end{array}$ & Cristóbal Serra & $\begin{array}{l}\text { Inglês- } \\
\text { Espanhol }\end{array}$ & $*$ & 1984 \\
\hline Espanha & $\begin{array}{l}\text { The Book of } \\
\text { Urizen }\end{array}$ & El libro de Urizen & $*$ & Madrid: Swan & Avantos Swan & $*$ & $*$ & 1984 \\
\hline Espanha & $\begin{array}{l}\text { Poetical } \\
\text { Sketches, An } \\
\text { Island in the }\end{array}$ & $\begin{array}{l}\text { Poesía Completa } \\
\text { (Tomo I; Tomo II) }\end{array}$ & $2^{a}$ & $\begin{array}{l}\text { Barcelona: } \\
\text { Ediciones } 29\end{array}$ & $\begin{array}{l}\text { Pablo Mañé Garzon } \\
\text { (correção e revisão: }\end{array}$ & $\begin{array}{l}\text { Inglês - } \\
\text { Espanhol }\end{array}$ & 4, em p\&b & 1984 \\
\hline
\end{tabular}




\begin{tabular}{|c|c|c|c|c|c|c|c|c|}
\hline & $\begin{array}{l}\text { Moon, The } \\
\text { Book of Thel, } \\
\text { Tiriel, Songs of } \\
\text { Innocence, } \\
\text { Songs of } \\
\text { Experience; } \\
\text { Rossetti } \\
\text { Manuscript (I), } \\
\text { Poems from } \\
\text { The Rossetti } \\
\text { Manuscript } \\
\text { (II), The } \\
\text { French } \\
\text { Revolution, } \\
\text { The Marriage } \\
\text { of Heaven and } \\
\text { Hell, Visions } \\
\text { of the } \\
\text { Daughters of } \\
\text { Albion }\end{array}$ & & & & $\begin{array}{l}\text { Enrique Caracciolo- } \\
\text { Trejo) }\end{array}$ & & & \\
\hline Espanha & {$[*]$} & $\begin{array}{l}\text { Poemas proféticos } \\
\text { y prosas }\end{array}$ & $*$ & $\begin{array}{l}\text { Seix-Barral: } \\
\text { Barcelona }\end{array}$ & Cristóbal Serra & $*$ & $*$ & 1984 \\
\hline Espanha & {$[*]$} & Poesía Completa & $*$ & $\begin{array}{l}\text { Barcelona: Edicion } \\
\text { es } 29\end{array}$ & Pablo Mañé Garzón & $*$ & $*$ & 1985 \\
\hline Espanha & {$[*]$} & Poesía Completa & $*$ & $\begin{array}{l}\text { Madrid: } \\
\text { Hyspamérica }\end{array}$ & Pablo Mañé Garzón & $*$ & $*$ & 1986 \\
\hline Espanha & {$[*]$} & Poesía Completa & $*$ & $\begin{array}{l}\text { Barcelona: Orbis } \\
\text { [Coleção } \\
\text { Biblioteca Personal } \\
\text { de Jorge Luis } \\
\text { Borges] }\end{array}$ & Pablo Mañé Garzón & $*$ & $*$ & 1986 \\
\hline
\end{tabular}




\begin{tabular}{|c|c|c|c|c|c|c|c|c|}
\hline Espanha & {$[*]$} & Poesía Completa & $3^{a}$ & $\begin{array}{l}\text { Barcelona: } \\
\text { Edicions } 62\end{array}$ & Pablo Mañé Garzón & $*$ & $*$ & 1986 \\
\hline Espanha & $\begin{array}{l}\text { Songs of } \\
\text { Innocence and } \\
\text { of Experience }\end{array}$ & $\begin{array}{l}\text { Canciones de } \\
\text { inocencia y de } \\
\text { experiencia }\end{array}$ & $*$ & Madrid: Cátedra & $\begin{array}{l}\text { José Luis Caramés; } \\
\text { Santiago González } \\
\text { Corugedo }\end{array}$ & $*$ & $*$ & 1987 \\
\hline Espanha & {$[*]$} & Poesía Completa & $4^{\mathrm{a}}$ & $\begin{array}{l}\text { Barcelona: } \\
\text { Ediciones } 29\end{array}$ & Pablo Mañé Garzón & $\begin{array}{c}\text { Inglês - } \\
\text { Espanhol }\end{array}$ & $*$ & 1995 \\
\hline Espanha & $\begin{array}{l}\text { Jerusalem, the } \\
\text { Emanation of } \\
\text { the Giant } \\
\text { Albion }\end{array}$ & $\begin{array}{l}\text { Jerusalén, la } \\
\text { emanación del } \\
\text { gigante Albión }\end{array}$ & $*$ & $\begin{array}{l}\text { Castellón de la } \\
\text { Plana: Universitat } \\
\text { Jaume I }\end{array}$ & $\begin{array}{l}\text { Javier Campos } \\
\text { Vilanova }\end{array}$ & $\begin{array}{l}\text { Inglês - } \\
\text { Espanhol }\end{array}$ & $*$ & 1997 \\
\hline Espanha & $\begin{array}{l}\text { Songs of } \\
\text { Innocence and } \\
\text { of Experience }\end{array}$ & $\begin{array}{l}\text { Cantos de } \\
\text { inocencia, cantos } \\
\text { de experiencia }\end{array}$ & $*$ & Barcelona: Orbis & Helena Valentí & $*$ & $*$ & 1998 \\
\hline Espanha & {$[*]$} & Poesía Completa & $5^{\mathrm{a}}$ & $\begin{array}{l}\text { Barcelona: } \\
\text { Ediciones } 29\end{array}$ & Pablo Mañé Garzón & $\begin{array}{l}\text { Inglês - } \\
\text { Espanhol }\end{array}$ & $*$ & 1998 \\
\hline Espanha & $\begin{array}{l}\text { Poetical } \\
\text { Sketches, } \\
\text { Songs, Thel, } \\
\text { Marriage, } \\
\text { America, } \\
\text { Urizen, The } \\
\text { Everlasting } \\
\text { Gospel }\end{array}$ & Antología bilíngue & $*$ & Madrid: Alianza & $\begin{array}{l}\text { Enrique Caracciolo } \\
\text { Trejo }\end{array}$ & $\begin{array}{l}\text { Inglês - } \\
\text { Espanhol }\end{array}$ & $*$ & 1998 \\
\hline Espanha & $\begin{array}{l}\text { Poetical } \\
\text { Sketches, } \\
\text { Island in the } \\
\text { Moon, Thel, } \\
\text { Tiriel, Songs, } \\
\text { Rossetti MS } \\
\text { poems, French }\end{array}$ & Poesía Completa & $*$ & Edicomunnicación & $\begin{array}{l}\text { Francesc LL. } \\
\text { Cardona }\end{array}$ & Espanhol & $*$ & 1999 \\
\hline
\end{tabular}




\begin{tabular}{|c|c|c|c|c|c|c|c|c|}
\hline & $\begin{array}{l}\text { Revolution, } \\
\text { The Marriage } \\
\text { of Heaven and } \\
\text { Hell }\end{array}$ & & & & & & & \\
\hline Espanha & $\begin{array}{l}\text { Songs of } \\
\text { Experience }\end{array}$ & $\begin{array}{l}\text { Cantos de la } \\
\text { experiencia }\end{array}$ & $*$ & $\begin{array}{l}\text { Molins de Rei, } \\
\text { Barcelona: Astri }\end{array}$ & Roberto Díaz & $*$ & $*$ & 2000 \\
\hline Espanha & $\begin{array}{l}\text { The Marriage } \\
\text { of Heaven and } \\
\text { Hell }\end{array}$ & $\begin{array}{l}\text { El matrimonio del } \\
\text { cielo y del infierno }\end{array}$ & $*$ & Hiperión & José Luis Palomares & $\begin{array}{c}\text { Inglês - } \\
\text { Espanhol }\end{array}$ & SIM & 2000 \\
\hline Espanha & $\begin{array}{l}\text { Seleção de } \\
\text { poemas líricos; } \\
\text { seleção de } \\
\text { cartas }\end{array}$ & $\begin{array}{l}\text { Los bosques de la } \\
\text { noche }\end{array}$ & $*$ & Pre-textos & Jordi Doce & $\begin{array}{c}\text { Inglês- } \\
\text { Espanhol }\end{array}$ & $*$ & 2001 \\
\hline Espanha & {$[*]$} & Obra poética & $3^{a}$ & $\begin{array}{l}\text { Sant Cugat del } \\
\text { Vallès: Ediciones } \\
29\end{array}$ & Pablo Mañé Garzón & $*$ & $*$ & 2001 \\
\hline Espanha & $\begin{array}{l}\text { The Book of } \\
\text { Urizen }\end{array}$ & El libro de Urizen & $1^{\mathrm{a}}$ & Madrid: Hiperión & José Luis Palomares & $\begin{array}{l}\text { Inglês - } \\
\text { Espanhol }\end{array}$ & $*$ & 2002 \\
\hline Espanha & $\begin{array}{l}\text { The Marriage } \\
\text { of Heaven and } \\
\text { Hell }\end{array}$ & $\begin{array}{l}\text { El matrimonio del } \\
\text { cielo y el infierno }\end{array}$ & $*$ & Madrid: Cátedra & Fernando Castanedo & $\begin{array}{l}\text { Inglês - } \\
\text { Espanhol }\end{array}$ & $*$ & 2002 \\
\hline Espanha & Milton a Poem & Milton: un poema & $*$ & $\begin{array}{l}\text { Barcelona: DVD } \\
\text { ediciones }\end{array}$ & Bel Atreides & $\begin{array}{l}\text { Inglês e } \\
\text { Espanhol }\end{array}$ & $*$ & 2002 \\
\hline Espanha & $\begin{array}{l}\text { All Religions } \\
\text { are One, There } \\
\text { is No Natural } \\
\text { Religion, The } \\
\text { Marriage of } \\
\text { Heaven and } \\
\text { Hell, } \\
\text { Descriptive }\end{array}$ & Prosa escogida & $*$ & $\begin{array}{l}\text { Barcelona: DVD } \\
\text { ediciones }\end{array}$ & Bel Atreides & Espanhol & $*$ & 2002 \\
\hline
\end{tabular}




\begin{tabular}{|c|c|c|c|c|c|c|c|c|}
\hline & $\begin{array}{l}\text { Catalogue, } \\
\text { Vision of the } \\
\text { Last Judgment, } \\
\text { Jerusalem } \\
\text { (excertos em } \\
\text { prosa) e } \\
\text { algumas cartas }\end{array}$ & & & & & & & \\
\hline Espanha & {$[*]$} & Antologia bilíngue & $*$ & Alianza Editorial & Enrique C. Trejo & $\begin{array}{c}\text { Inglês - } \\
\text { Espanhol }\end{array}$ & $*$ & 2002 \\
\hline Espanha & {$[*]$} & Poesías completas & $*$ & Barcelona: RBA & Pablo M. Garzón & Espanhol & $*$ & 2002 \\
\hline Espanha & $\begin{array}{l}\text { The Marriage } \\
\text { of Heaven and } \\
\text { Hell }\end{array}$ & $\begin{array}{l}\text { El matrimonio del } \\
\text { cielo y el infierno }\end{array}$ & $1^{\mathrm{a}}$ & Editora Catedra & $*$ & Espanhol & SIM & 2002 \\
\hline Espanha & $\begin{array}{l}\text { The Marriage } \\
\text { of Heaven and } \\
\text { Hell/Songs of } \\
\text { Experience }\end{array}$ & $\begin{array}{l}\text { Matrimonio del } \\
\text { cielo y del infierno/ } \\
\text { Los cantos de } \\
\text { experiencia }\end{array}$ & $*$ & Madrid: C Libros & $*$ & $*$ & $*$ & 2003 \\
\hline Espanha & {$[*]$} & $\begin{array}{l}\text { Blake. Poesía } \\
\text { Completa }\end{array}$ & $6^{\mathrm{a}}$ & $\begin{array}{l}\text { Barcelona: } \\
\text { Ediciones } 29\end{array}$ & Pablo Mañé Garzón & Espanhol & $*$ & 2003 \\
\hline Espanha & $\begin{array}{l}\text { The Marriage } \\
\text { of Heaven and } \\
\text { Hell }\end{array}$ & $\begin{array}{l}\text { El matrimonio del } \\
\text { cielo y del infierno }\end{array}$ & $*$ & $\begin{array}{l}\text { Madrid: Ediciones } \\
\text { Hiperión }\end{array}$ & $*$ & $*$ & $*$ & 2005 \\
\hline Espanha & $\begin{array}{l}\text { The Book of } \\
\text { Thel }\end{array}$ & $\begin{array}{l}\text { Tiriel: El libro de } \\
\text { Thel }\end{array}$ & $*$ & $\begin{array}{l}\text { Madrid: Artemisa } \\
\text { ediciones }\end{array}$ & $*$ & $*$ & $*$ & 2006 \\
\hline Espanha & $\begin{array}{l}\text { Songs of } \\
\text { Innocence and } \\
\text { Experience }\end{array}$ & $\begin{array}{l}\text { Canciones de } \\
\text { inocencia y de } \\
\text { experiencia }\end{array}$ & $5^{\mathrm{a}}$ & Editora Catedra & $*$ & Espanhol & $*$ & 2006 \\
\hline Espanha & $\begin{array}{l}\text { The Marriage } \\
\text { of Heaven and } \\
\text { Hell }\end{array}$ & $\begin{array}{l}\text { El matrimonio del } \\
\text { cielo y del infierno }\end{array}$ & $*$ & $\begin{array}{l}\text { Sevilla: } \\
\text { Renacimiento }\end{array}$ & Xavier Villaurrutia & $*$ & $*$ & 2007 \\
\hline
\end{tabular}




\begin{tabular}{|c|c|c|c|c|c|c|c|c|}
\hline Espanha & [*] & $\begin{array}{l}\text { Ver un mundo en } \\
\text { un grano de arena }\end{array}$ & $*$ & $\begin{array}{l}\text { Madrid: Visor } \\
\text { Libros }\end{array}$ & Jordi Doce & $\begin{array}{c}\text { Inglês - } \\
\text { Espanhol }\end{array}$ & $*$ & 2009 \\
\hline Espanha & \begin{tabular}{|l} 
A Selection \\
from Reynolds \\
Discourses on \\
Art with \\
William \\
Blake's \\
complete \\
Marginalia \\
\end{tabular} & $\begin{array}{l}\text { Discursos sobre } \\
\text { arte. Anotaciones } \\
\text { de William Blake }\end{array}$ & $*$ & $\begin{array}{l}\text { San Lorenzo de El } \\
\text { Escorial: C. de } \\
\text { Langre }\end{array}$ & $\begin{array}{l}\text { José Luis Palomares } \\
\text { y Blanca Guinea }\end{array}$ & Espanhol & - & 2011 \\
\hline Espanha & $\begin{array}{l}\text { The Marriage } \\
\text { of Heaven and } \\
\text { Hell \& Songs } \\
\text { of Innocence } \\
\text { and of } \\
\text { Experience }\end{array}$ & $\begin{array}{l}\text { Matrimonio del } \\
\text { cielo y el infierno; } \\
\text { Cantos de } \\
\text { inocencia; Cantos } \\
\text { de experiencia }\end{array}$ & $1^{\mathrm{a}}$ & Madrid: Visor & Soledad Capurro & $\begin{array}{l}\text { Inglês - } \\
\text { Espanhol }\end{array}$ & $*$ & 2011 \\
\hline Espanha & $\begin{array}{l}\text { The Book of } \\
\text { Thell The } \\
\text { Marriage of } \\
\text { Heaven and } \\
\text { Hell/ The } \\
\text { French } \\
\text { Revolution/ } \\
\text { Visions of the } \\
\text { Daughters of } \\
\text { Albion/ } \\
\text { America a } \\
\text { Prophecy/ } \\
\text { Europe a } \\
\text { Prophecy/ The } \\
\text { (First) Book of }\end{array}$ & Libros proféticos I & $*$ & Atalanta & $\begin{array}{l}\text { Bernardo Santano } \\
\text { Moreno }\end{array}$ & $\begin{array}{c}\text { Inglês - } \\
\text { Espanhol }\end{array}$ & SIM & 2013 \\
\hline
\end{tabular}




\begin{tabular}{|c|c|c|c|c|c|c|c|c|}
\hline & $\begin{array}{l}\text { Urizen/ The } \\
\text { Book of } \\
\text { Ahania/ The } \\
\text { Book of Los/ } \\
\text { The Song of } \\
\text { Los/ Vala, or } \\
\text { The Four Zoas }\end{array}$ & & & & & & & \\
\hline Espanha & $\begin{array}{l}\text { Milton: A } \\
\text { Poem in Two } \\
\text { Books/ } \\
\text { Jerusalem The } \\
\text { Emanation of } \\
\text { the Giant } \\
\text { Albion }\end{array}$ & Libros proféticos II & $*$ & Atalanta & $\begin{array}{l}\text { Bernardo Santano } \\
\text { Moreno }\end{array}$ & Espanhol & SIM & 2014 \\
\hline Espanha & $\begin{array}{l}\text { An Island in } \\
\text { the Moon }\end{array}$ & Uma isla en la luna & $*$ & $\begin{array}{l}\text { Madrid: Ediciones } \\
\text { Cátedra }\end{array}$ & Fernando Castanedo & $*$ & $*$ & 2014 \\
\hline Espanha & $\begin{array}{l}\text { All religions } \\
\text { are One; There } \\
\text { is No Natural } \\
\text { Religion }\end{array}$ & $\begin{array}{l}\text { Todas las } \\
\text { religiones son una / } \\
\text { No hay religión } \\
\text { natural }\end{array}$ & $*$ & Pregunta Ediciones & David Francisco & Espanhol & $*$ & 2014 \\
\hline
\end{tabular}


A pesquisa realizada confirma que a obra de William Blake é considerada relevante no contexto das literaturas de língua espanhola, sendo que há registros de 65 edições, no total, de títulos do autor publicados na Argentina (9 edições), no México (7 edições), no Uruguai (1 edição) e na Espanha (48 edições). Considerando que algumas traduções foram reeditadas, o presente estudo encontrou um total de 38 traduções publicadas em língua espanhola (6 delas publicadas na Argentina, 5 no México, 1 no Uruguai e 26 na Espanha). Vale mencionar que foram encontrados vários títulos publicados por editoras espanholas, como a editora Cátedra e a editora Atalanta, no acervo de bibliotecas nacionais da América Latina, o que aponta uma interação significativa entre os sistemas de literatura traduzida das literaturas de língua espanhola.

De acordo com os dados reunidos até o momento, a história das edições de obras de Blake em espanhol se inicia com La boda del Cielo y del Infierno, tradução de Edmundo González-Blanco publicada pela editora Mundo Latino em 1928. Contudo, Gimeno Suances (2003) informa que, antes da tradução de González-Blanco, vieram a público três poemas traduzidos por Salvador de Madariaga: Never Seek to Tell thy Love e The Clod and the Pebble, 204 incluídos primeiramente em Ensayos angloespañoles (1922). De todo modo, nas palavras de Gimeno Suances (2003, p. 02):

\footnotetext{
Una visión general de la obra blakeana, sin embargo, sólo sería posible a raíz de la publicación de La boda del Cielo y del Infierno (Primeros libros proféticos) (1928), traducido y anotado por Edmundo González-Blanco, autor además de una extensa introducción (pgs. 5-82). El equívoco título de la obra ha inducido generalmente a reducir su auténtica importancia, pues se ha creído que incluía únicamente la traducción del Marriage, cuando, de hecho, ofrece versiones completas en prosa de todos los libros proféticos anteriores a The Four Zoas.
}

Gimeno Suances informa ainda que a tradução realizada por González-Blanco foi mediada pelas traduções francesas de Pierre Berger. Sobre a introdução escrita pelo tradutor espanhol para La boda del Cielo y del Infierno, Gimeno Suances (2003, p. 03) observa que:

\footnotetext{
parece encaminada a estructurar un "sistema blakeano" interrelacionado con el desarrollo de la filosofía ilustrada y decimonónica (...), si bien el autor, acorde a la tradición academicista predominante en Berger, su fuente principal, se inclina al cabo por una interpretación de corte "místico" tendente a enlazar a Blake con las tradiciones gnósticas, neoplátonicas, etc.
}

O levantamento realizado mostra que as edições de traduções de Blake ressurgem na década de 1940. Nesta década, foi publicada a que parece ser a primeira tradução (em livro) de 
Blake da América Latina de língua espanhola, El matrimonio del cielo y del infierno (Séneca, 1942), realizada pelo poeta e dramaturgo mexicano Xavier Vilaurrutia.

Parece ter havido um declínio do número de traduções de Blake nas décadas de 1950 e 1960 - temos notícia de apenas uma tradução publicada neste período, na Argentina, em 1957: Poemas y profecías, da editora Assandri. O interesse pelo poeta inglês retornará na década de 1970, quando foram publicadas várias edições em língua espanhola, tanto na Europa como na América Latina. O volume de traduções seria ainda maior na década de 1980. Com base na relação de traduções apresentada, é possível dizer que, desde a década de 1970, a obra de Blake está continuamente presente no mercado literário de língua espanhola na forma de edições e reedições de traduções de poesia e prosa do autor inglês.

De acordo com os dados obtidos, o título mais traduzido de Blake para o espanhol é The Marriage of Heaven and Hell (obra na qual se encontram os famosos Proverbs of Hell). Levando em conta as traduções deste livro (incluindo aquelas publicadas em coletâneas como Poesía Completa) cujos tradutores puderam ser identificados, existem 8 traduções diferentes deste livro em língua espanhola:

- La boda del Cielo y del Infierno, tradução de Edmundo González-Blanco. Madri: Editorial Mundo Latino, 1928.

- Poesía Completa (Tomo I; Tomo II), Pablo Mañé Garzon (correção e revisão: Enrique Caracciolo-Trejo). Barcelona: Ediciones 29, 1980, 1984, 1986, 1995, 1998, 2001, 2003. Barcelona: Orbis, 1985. Madri: Hyspamérica, 1986. Barcelona: RBA, 2002.

- El matrimonio del cielo y el infierno, tradução de Fernando Castanedo. Madri: Cátedra, 2002

- El matrimonio del cielo y del infierno, tradução de José Luis Palomares. Madri: Hiperión, 2000.

- (El) matrimonio del cielo y del infierno, tradução de Xavier Vilaurrutia. Cidade do México: Séneca, 1942; Editora Veracruz, 2003; Fontamara, 2007. Sevilla: Renacimiento, 2007.

- Libros proféticos I, tradução de Bernardo Santano Moreno. Vilaür: Atalanta, 2013.

- Matrimonio del cielo y el infierno, tradução de Diego Arenas. Buenos Aires: Galerna, 1979. 
- El matrimonio del cielo y del infierno; Cantos de inocencia y de experiencia, tradução de Soledad Capurro. Madrid: Alberto Corazón, 1979; Visor, 1979, 1983; Buenos Aires: Continente, 2011.

Songs of Innocence and of Experience (onde está o célebre poema The Tyger) também recebeu considerável atenção de editoras e tradutores; a relação de publicações obtida apresenta 7 traduções deste livro, incluindo aquelas publicadas em coletâneas como Poesía Completa (observa-se, contudo, que nem todas trazem o par Songs of Innocence and of Experience, mas apenas Songs of Innocence ou Songs of Experience, conforme descrito a seguir). Tais traduções foram realizadas por Helena Valentí, por Soledad Capurro, por Pablo Mañé Garzón (em Poesía Completa), pelo tradutor e escritor espanhol José Luis Caramés em parceria com Santiago González Corugedo, pelo tradutor e poeta argentino Roberto Díaz, pela tradutora e poeta argentina Mirta Rosenberg e pelo tradutor argentino Miguel Grinberg (também "traductor de la obra de Allen Ginsberg”, entre outros, segundo Vespa, 2014):

- Cantos de inocencia, cantos de experiencia, tradução de Helena Valentí. Barcelona: Bosch, 1977. Barcelona: Orbis, 1998.

- El matrimonio del cielo y del infierno; Cantos de inocencia y de experiencia, tradução de Soledad Capurro. Madri: Alberto Corazón, 1979; Visor, 1979, 1983; Buenos Aires: Continente, 2011.

- Poesía Completa (Tomo I; Tomo II), Pablo Mañé Garzon (correção e revisão: Enrique Caracciolo-Trejo). Barcelona: Ediciones 29, 1980, 1984, 1986, 1995, 1998, 2001, 2003. Barcelona: Orbis, 1985. Madri: Hyspamérica, 1986. Barcelona: RBA, 2002.

- Canciones de inocencia y de experiencia, tradução de José Luis Caramés; Santiago González Corugedo. Madri: Cátedra, 1987.

- Cantos de la experiencia, tradução de Roberto Díaz. Barcelona: Astri, 2000.

- Cantos de Inocencia, tradução de Mirta Rosenberg. Buenos Aires: Adiax, 1980.

- Cantares de Inocencia y Experiencia: que Muestran los Dos Estados Contrarios del Alma Humana, de tradução de Miguel Grinberg. Buenos Aires: Errepar, 2000.

The Book of Thel apresenta 7 edições em espanhol; os tradutores identificados de 5 das traduções são Jordi Doce, Hernando Valencia Goelkel, Bernardo Santano Moreno, Pablo Mañé Garzon e Edmundo González-Blanco. 
The Book of Urizen, por sua vez, conta 3 traduções em espanhol, dos tradutores Avantos Swan, José Luis Palomares e N.N. Existe, ainda, uma tradução de An Island in the Moon, Una isla en la luna, de Fernando Castanedo, e também uma edição que contém All Religions Are One e There Is No Natural Religion, tradução de David Francisco: ambas as edições são de 2014. A única tradução de Jerusalem não publicada em coletânea é de Javier Campos Vilanova, de 1997. Uma tradução de Milton, de Bel Atreides, foi publicada em uma edição da DVD Ediciones em 2002, e uma tradução de The Everlasting Gospel, de Evelio Roas Robles, foi publicada pela Ediciones Arsenal em 2006.

As literaturas em língua espanhola dispõem de um bom número de coletâneas de textos traduzidos de Blake. As coletâneas chamam atenção por sua abrangência de títulos do poeta inglês, desde seus textos iniciais até as profecias de sua fase madura:

- La boda del Cielo y del Infierno, tradução de Edmundo González-Blanco. Madri: Editorial Mundo Latino, 1928.

- Poemas proféticos y prosas, tradução de Cristóbal Serra. Barcelona: Editora Barral, 1971. Madrid: Júcar, 1984 [Antología].

- Poesía Completa (Tomo I; Tomo II), Pablo Mañé Garzon (correção e revisão: Enrique Caracciolo-Trejo). Barcelona: Ediciones 29, 1980.

- Antología bilíngue, tradução de Enrique Caracciolo Trejo. Madrid: Alianza, 1998.

- Poesía Completa, tradução de Francesc LL. Cardona. Barcelona: Edicomunnicación, 1999.

- Prosa escogida, tradução de Bel Atreides. Barcelona: DVD Ediciones, 2002.

- Libros proféticos I, tradução de Bernardo Santano Moreno. Vilaür: Atalanta, 2013.

- Libros proféticos II, tradução de Bernardo Santano Moreno. Vilaür: Atalanta, 2014.

- Visiones, tradução de Enrique C. Trejo. Cidade do México: Editora Era, 1974.

- Primeros libros proféticos: poemas, tradução de Agustí Bartra. Cidade do México: UNAM, 1990.

- El demonio es parco: aforismos, tradução de Heriberto Yépez. Cidade do México, Verdehalago, 2006.

- Poesía Completa, tradução de Andrés Maldonado. [Argentina:] Cygnus Regalis, 2012. 
Embora nenhuma das coletâneas publicadas em língua espanhola aparentemente apresente a totalidade da obra de Blake, três delas trazem conjuntos amplos: La boda del Cielo y del Infierno, tradução de Edmundo González-Blanco (1928), Poesía Completa, tradução Pablo Mañé Garzon (1980), e Libros proféticos I/Libros proféticos II, tradução de Bernardo Santano Moreno (2013/2014). As três edições são espanholas (sobre a edição mexicana Poesía Completa, tradução de Andrés Maldonado, publicada em 2012, não foram encontradas informações relativas aos textos que ela reúne).

Já mencionamos a importância da seleção de textos traduzidos por Edmundo GonzálezBlanco em La boda del Cielo y del Infierno, embora "La difusión de esta edición es difícil de estabelecer" (GIMENO SUANCES, 2003, p. 03). Diz Gimeno Suances (2003, p. 03) que a edição "no fue mencionada por Jiménez, Unamuno ni Neruda, y tanto Bentley como Young han aludido a ella como si contuviera únicamente la traducción del Marriage". Ainda assim,

resulta indudable que la existencia desde 1928 de una versión castellana de los poemas proféticos de Lambeth arroja nueva luz sobre ciertas posibles 'influencias' blakeanas en poetas hispánicos poco familiarizados por entonces con la lengua inglesa (Juan Ramón, Lorca, Cernuda). (GIMENO SUANCES, 2013, p. 03)

De outro lado, a edição de Poesía Completa (cuja data de publicação original é, de acordo com os registros encontrados, 1980), com traduções do uruguaio Pablo Mañé Garzón responsável também pela tradução das "obras completas de Shakespeare (sonetos), Whitman, Mallarmé", entre outras traduções de "numerosos poetas ingleses, franceses y americanos" (PABLO, 2016) -, parece ter alcançado ampla circulação, sendo disponibilizada ao público várias vezes por diferentes editoras. Existem ao menos 7 edições desta coletânea publicadas pela Ediciones 29. No Prólogo à sua tradução, Garzón (1984, p. 7) destaca um perfil de Blake como visionário e também como "un creador formal novedoso": "los esfuerzos de Blake tras una especie nueva de expresión que, aunque parcialmente falida e incapaz de generar la atención sobre las múltiples tentativas del genio por hallar el médio adecuado a um modo personal de sentir" (GARZÓN, 1984, p. 10). Apesar de estabelecer uma perceptível separação entre o poeta e o gravurista e pintor, deixando de lado o aspecto pictórico ao discutir elementos da nova expressão almejada por Blake, Garzón encerra seu Prólogo “invitando al lector especialmente interesado em la obra escrita e dibujada de Blake que consulte las ediciones facsimiladas que se han editado últimamente en Inglaterra y Estados Unidos” (p. 12).

O esforço mais recente de reunir um grande número de textos de Blake em espanhol, Libros proféticos I/Libros proféticos II (2013/2014), em traduções de Bernardo Santano 
Moreno, professor de Filologia Inglesa na Universidad de Extremadura e pesquisador de cultura inglesa medieval (UNEX, 2016), destaca, justamente, a sua singular combinação de texto e imagem. A apresentação do Tomo I desta edição na página da editora Atalanta inicia com uma citação da escritora e tradutora mexicana Adriana Díaz Enciso sobre o projeto de incluir a reprodução das gravuras:

La publicación bilingüe de Ediciones Atalanta de los Libros Proféticos íntegros, con reproducción de las ilustraciones, en dos volúmenes (el segundo aparecerá a principios de 2014) es de una relevancia suprema para la comprensión de esta obra en el mundo de habla hispana. (ATALANTA, 2016)

Em artigo (MASSOT, 2014) compartilhado no mesmo site, o tradutor, Moreno, argumenta que "William Blake desarrolló un sistema propio de grabado, concibió texto e imagen como una unidad, y por ello el lector debe acercarse a los Libros proféticos combinando los dos elementos". Ainda neste artigo (MASSOT, 2014), o diretor da editora, Jacobo Siruela, defende a atualidade da obra de Blake como crítico da modernidade: "En un mundo, como el de hoy, en el que el dinero es el principal valor, el destrozo de la naturaleza es cada vez más despiadado y el vacío existencial tan notorio, su poesía y sus ideias cobran una vitalidad y actualidad enormes".

O ingresso da obra de William Blake nos sistemas literários de língua espanhola via tradução ocorreu cedo ${ }^{4}$, em 1928, com La boda del Cielo y del Infierno, resultado do contato com traduções francesas, segundo Gimeno Suances (2003). O livro que dá título a esta primeira tradução, The Marriage of Heaven and Hell, destaca-se entre os textos selecionados pelo sistema de literatura traduzida de língua espanhola, assim como Songs of Innocence and of Experience. Estas são, de fato, as obras mais famosas do autor de modo geral, e costumam ser as mais lembradas entre os leitores não profissionais e os leitores indiretos.

A aparente preferência por The Marriage of Heaven and Hell e Songs of Innocence and of Experience, contudo, não impediu o aparecimento de coletâneas abrangentes de textos do autor inglês. Há um número expressivo de coletâneas de Blake em espanhol, e elas são a principal contribuição para a presença da obra do autor em sua quase totalidade neste idioma.

De acordo com a pesquisa realizada, a maioria das edições não inclui reprodução das gravuras dos livros iluminados de Blake, sendo que, aparentemente, a preocupação das editoras 
com o aspecto pictórico de sua obra poética é recente, em parte seguindo, talvez, a tendência contemporânea para a intermidialidade nas artes e o atual interesse dos estudos literários na questão da materialidade da literatura. Segundo Gimeno Suances (2003), a primeira edição facsimilar de um livro iluminado de Blake publicada na Espanha é Matrimonio del cielo y del infierno (Hiperión, 2000). Libros Proféticos I/ Libros Proféticos II (Atalanta, 2013/2014) é um projeto importante em termos de edição fac-similar.

Na Apresentação de seu projeto Poesia Traduzida no Brasil, Marlova Aseff (2016) observa:

\footnotetext{
É sabido que, atualmente, pesquisadores de variadas áreas - Literatura Comparada, Estudos da Tradução ou mesmo Estudos Culturais - encontram muitas dificuldades para ter acesso ao conjunto de títulos que circulou em forma de tradução no sistema literário brasileiro em cada período histórico.
}

Durante a busca de publicações de textos de Blake em língua espanhola, encontramos dificuldades semelhantes, como a falta de informações em fontes confiáveis. As bibliografias de Bentley Jr (2015), consultadas ao final da pesquisa, ajudaram a solucionar dúvidas e a completar dados de várias traduções.

Para uma avaliação mais precisa da imagem literária de Blake em espanhol, seria importante incluir, em uma eventual continuação do estudo, as traduções publicadas em outros meios além do livro, como os periódicos. Sem dúvida, há informações importantes nos periódicos e suplementos literários, como a tradução de The Book of Thel (El libro de Thel) realizada pelo crítico, ensaísta e tradutor colombiano Hernando Valencia Goelkele e publicada na influente revista Mito, bem como as traduções de Pablo Neruda, Visiones de las hijas de Albión e El viajero mental (Visions of the Daughters of Albion; The Mental Traveller), publicadas na revista Cruz y Raya em 1934 (GIMENO SUANCES, 2003) ${ }^{5}$.

O aprofundamento da pesquisa também levaria em consideração uma análise detalhada dos paratextos das traduções - prefácios e notas, por exemplo, e os estudos críticos, resenhas, entre outros elementos. Uma análise das próprias traduções seria central para mostrar as decisões e ênfases realizadas pelos tradutores em relação à poesia e à prosa de Blake. 


\section{REFERÊNCIAS}

ASEFF, Marlova. Poesia Traduzida no Brasil. Disponível em: <http://poesiatraduzida.com.br/>. Acesso em: 20 jul. 2016.

ATALANTA, Editorial. Libros proféticos. Tomo I. Disponível em: <http://www.atalantaweb.com/libro.php?id=94>. Acesso em: 20 jul. 2016.

BENTLEY Jr, Gerald Eades. William Blake \& His Circle: Publications and Discoveries from 1992. 2015.2 Disponível em: <http://library.vicu.utoronto.ca/collections/special_collections/bentley_blake_collection/blake _circle/William_Blake_and_His_Circle.pdf>. Acesso em: 20 jul. 2016.

EVEN-ZOHAR, Itamar. A Posição da Literatura Traduzida dentro do Sistema Literário. Tradução de Leandro de Ávila Braga. Translatio, Porto Alegre, p.1-10, 2012. Disponível em: <http://seer.ufrgs.br/index.php/translatio/article/view/34674/22321>. Acesso em: 10 jul. 2016.

EVEN-ZOHAR, Itamar. Polysystem Studies. Poetics Today, Durham, v. 11, n. 1, p.1-268, 1990. Disponível em: <http://www.tau.ac.il/ itamarez/works/papers/trabajos/EZ-teoriapolisistemas.pdf >. Acesso em: 03 jun. 2016.

GIMENO SUANCES, Francisco. Notas sobre la difusión, influencia y recepción crítica de la obra de William Blake en España durante las décadas de 1920 y 1930. Los Papeles Mojados de Río Seco, Estepa, Año 5, nº 6, 2003.

LEFEVERE, André. Tradução, reescrita e manipulação da fama literária. Tradução de Claudia Matos Seligmann. Bauru: Edusc, 2007.

MASSOT, Josep. Blake, poesía contra el materialismo: Atalanta publica por primera vez "Los libros proféticos" con todos los grabados, como lo ideó el poeta romántico. La Vanguardia. Barcelona, p. 39. 28 abr. 2014. Disponível em: <http://www.atalantaweb.com/libro.php?id=94>. Acesso em: 20 jul. 2016.

PABLO Mañé. Disponível em: <http://www.pablomane.com/index.html>. Acesso em: 26 ago. 2016.

UNEX. Bernardo

Santano

Moreno. Disponível

em:

<http://www3.unex.es/publicaciones/files/1415-B. Santano Moreno.pdf>. Acesso em: 26 ago. 2016.

VESPA, Mariano. Grinberg y los beats: entrevista. 2014. Disponível em: <https://revistapaco.com/2014/08/21/grinberg-y-los-beats/>. Acesso em: 27 ago. 2016.

\footnotetext{
${ }^{1}$ Juliana STEIL - Doutora (2011) e Mestre (2007) em Estudos da Tradução pela Universidade Federal de Santa Catarina (UFSC). Graduada em Letras (2004) pela Universidade do Vale do Itajaí (Univali).

Currículo Lattes Juliana Steil: http://lattes.cnpq.br/5586916987453183.

${ }^{2}$ Vitória Tassara Costa SILVA - Bolsista remunerada do Projeto "William Blake em tradução: The Four Zoas".

Currículo Lattes Vitória Tassara Costa Silva. Disponível em: http://lattes.cnpq.br/1017840206313804.
} 


\footnotetext{
${ }^{3}$ Não foram encontradas referências de livros do autor traduzidos para o espanhol e publicados em outros países hispano-americanos. Os espaços marcados com um asterisco $(*)$ indicam que as informações correspondentes não foram encontradas.

${ }^{4}$ Em comparação com as literaturas de língua portuguesa, por exemplo, que tiveram a sua primeira tradução de Blake publicada na década de 1950: Núpcias do Céu e do Inferno, tradução de Oswaldino Marques. Rio de Janeiro: Francisco Alves, 1956.

${ }^{5}$ Gimeno Suances $(2003$, p. 07) avalia que Neruda "contribuyó de manera decisiva a la difusión de la poesía blakeana en España gracias a su traducción de Visiones de las Hijas de Albión, junto al poema 'El viajero mental', en la revista Cruz y Raya en 1934".
}

RECEBIDO EM: 09 de outubro de 2016

ACEITO EM: 15 de dezembro de 2016

PUBLICADO EM: Dezembro de 2016 